\title{
É preciso individuar a cidade
}

Franciscu Sedda

Professor e Pesquisador em Semiótica da Cultura na Universidade de Roma "Tor Vergata". Integra atualmente como pesquisador um projeto de cooperação internacional junto a Pontifícia Universidade Católica de São Paulo (PUC-SP) e de Roma "La Sapienza". Parte dos resultados deste trabalho encontra-se no ensaio "Semiopolitica das culturas" (Roma 2012).

Resumo: Este breve ensaio aborda a problemática da individuação da cidade através de uma serie de operaçóes semióticas. Em particular, discute-se da delimitação e da nominaçáo que a constituem enquanto sujeito que possui uma personalidade e uma memória própria. Ao mesmo tempo, a cidade se mostra como um objeto de valor, em volta do qual convergem e colidem diferentes visóes do espaço, do pertencimento e da mesma cidade concebida como um "bem comum".

Palavra-chave: Cidade; Espacialidade; Tradução.

Abstract: This short article explores the problem of the identification of the city through a series of semiotic actions such as delimitation and nomination. These semiotic devices contribute to constitute the city as a subject provided with personality and memory. At the same time the city can be regarded as an object of value through which different visions of space, belonging and common good are developed.

Keywords: City; Spatiality, Translation. 
A cidade, entre multiplicidade fenomênica e globalidade de sentido.

A cidade pode ser um "bem comum"?

Para responder a esta pergunta é preciso, ao menos, concordar sobre a existência do objeto-cidade, especialmente em um momento em que, à evidente metropolitanização do globo evidenciada por geógrafos e urbanistas, corresponde, no olhar do cientistas sociais, a percepção de que a cidade esteja, aos poucos, cedendo, abdicando de sua forma, de sua singularidade e de sua identificabilidade.

Na perspectiva da semiótica, o problema ganha, porém, outras nuances, que transformam a cidade num objeto de analise talvez mais complexo, aparentemente mais evasivo e recalcitrante - e, todavia, não muito diferente de outras formaçôes semióticas, como, por exemplo, um texto literário ou um filme.

A questão é a seguinte: como uma multiplicidade fenomênica se constituiu e se dá a ver como uma globalidade de sentido. Ou, ainda, como a heterogeneidade que nos enfrenta e em que estamos imersos ganha - a partir de um determinado ponto de vista, ou seja, dentro de uma específica relação diferencial - uma unidade, uma forma de articulação de sua pluralidade, de sua concordância discordante, qualquer que ela seja: uma harmoniosa polifonia, um tenso contraponto ou uma cacofonia levada ao limite do inaudível, reconhecível justamente por suas evidentes e irritantes dissonâncias.

\section{As delimitaçôes semióticas da individuação da cidade.}

Um caso muito claro deste jogo de construção de sentido da cidade, que se reflete e se expande nos níveis multíplices e microscópicos que a constituem, é representado pelo problema de sua individuação a partir de uma serie de operaçóes de delimitação semiótica.

Operaçôes de delimitação que, no presente vivo do espaço metropolitano encontram-se muitas vezes em um estado de co-presença, concorrência ou até de declarado conflito. É o que acontece no nível mais abstrato das definiçóes culturais do espaço citadino. Diante de Roma Caput Mundi, Cidade Eterna, SPQR, Comune di Roma, Roma Capitale, La Lupa, poderíamos nos perguntar, por exemplo, qual destas de-finiçôes representa melhor Roma? Qual delas a circunscreve de forma mais efetiva e eficaz, devolvendo a imagem de sua multiplicidade fenomênica, diacrônica e sincrônica?

A este tipo de operações semióticas acrescentam-se outras delimitaçôes que agem na dimensão física-temporal. Operaçôes de delimitação cuja peculiaridade é seu correr atrás de si próprias e seu continuo recrear-se, assumindo as formas da cauda do serpente que, uma vez cortada, volta novamente a crescer.

Roma ultrapassa diversas vezes os muros que deveriam decretar sua forma. E mesmo quando a urbe - outra definição que precisa ser incluída no elenco precedente - parece exorbitar a possibilidade de traçar um confim espacial, eis que aparece, de forma reflexiva, graças à convergência de uma serie de operaçóes semióticas muito diferentes, a figura limar do Grande Raccordo Anulare (GRA) (1). 
O discurso urbanístico que constitui e identifica o GRA como o limite denso da cidade; o dirigir pelo Grande Raccordo que, mesmo por um breve trecho, consolida a sensação de poder circunvagar a cidade, de podê-la englobar totalmente; a histórica paródia de um dos maiores músicos italianos, Antonello Venditti, feita pelo comediante Corrado Guzzanti, romano como o próprio Venditti ("Vem comigo amor/no Grande Raccordo Anulare/que circunda a Capital/e nas paradas faremos amor/E se nasce uma menina, depois, a chamaremos... Roma”); o sucesso do filme documentário de Gianfranco Rosi Sacro-G.R.A, que ganhou o Leone d'Oro no Festival de Cinema de Veneza. Tudo isso e muito mais contribui para recriar um confim - um dos possíveis confins - da cidade e, também, a evidenciar a significatividade como espaço de vida, ressaltando a sacralidade ambígua e a ritualidade de seu atravessamento (seja este um ultrapassar ou um percorrer), apontando os refletores sobre a vida que passa por cima, por baixo e em volta da urbe.

Portanto, o Grande Raccordo Anulare é mesmo o confim da Roma contemporânea? Claro que não! teríamos que dizer. Em primeiro lugar porque ele disputa este papel delimitador com outros mapas da cidade, em particular aquele aparentemente mais exato - e entretanto historicamente móvel e negociável - da fronteira administrativa do território metropolitano. A cidade, ou seja, parece individuar o seu próprio limite apenas para ultrapassá-lo e - novamente - recriá-lo.

Pequim chegou agora na sua sexta "Ring Road", o seu sexto Grande Raccordo Anulare. Quantos outros Grande Raccordo Anulare marcarão, um dia, o confim de Roma?

\section{Um espaço-em-comum}

Poderíamos afirmar, voltando à pergunta colocada no início deste artigo, que o recriar-se do confim recria o sentido de um espaço em comum. Um espaço compartilhado e para compartilhar. $\mathrm{O}$ que poderia significar, também, o reconhecimento de um bem comum, ou, ao menos, a base de sentido, a base sensível através da qual atuar o reconhecimento de um bem a ser compartilhado. No entanto, a ideia de um "bem" implica a presença de uma comunidade que se reúna em torno de uma ideia de cidade, do que é justo para ela e para quem a abita. Muitas vezes, o espaço-em-comum que a cidade representa é apenas - mas às vezes isso já é muito - um suporte para reconhecer um campo de jogo e de conflito para as partes que a abitam, sejam essas indivíduos, grupos, organismos, organizaçóes, instituiçóes públicas e privadas. Neste sentido, o espaço citadino, antes de ser um bem público, é aquele elemento sobre o qual se desenvolvem as diversas ideias do que é bom que a cidade seja.

\section{Conflito de nomes. Ou da cidade como objeto de valor}

Este conflito sobre os valores da cidade, sobre o valor que a cidade tem que adquirir, sobre o que a cidade precisa valorizar para poder dar valor a si mesma e aos seus habitantes, alcança o grau zero quando a própria cidade torna-se o objeto de valor em jogo, a aposta sobre a qual se desenvolve o conflito entre as coletividades que não apenas almejam a possuí-la, mas que visam, ao 
mesmo tempo, se afirmar enquanto comunidades através da conjunção com ela.

O grande testemunha deste jogo que envolve, no nível mais básico, a relação e a constituição recíproca entre o espaço e a comunidade é o outro fator de individuação da cidade: o nome

Poderíamos dizer que a emersão do nome da cidade é o resultado do encontro entre o espaço e a comunidade, e também, retrospectivamente, o signo que demonstra e sanciona a realização da comunicação entre os dois elementos.

Trata-se de uma dinâmica que emerge com clareza no ato de fundação da cidade, que, no mito, é sempre representado com um ato de nominação da cidade. Porém, esse processo torna-se ainda mais claro nos momentos de crise e de transformaçáo das cidades, quando a questão do nome - e de quem seria aquele que tem o dever e o poder de nomeá-la - reafirma-se de modo lacerante.

Nieuw-Amsterdam que se torna New York. Bombay que vira Mumbai. Atrás da mudança de nome se esconde uma mudança ou um conflito de pertencimento. Ou melhor, um conflito sobre um espaço que pertence à comunidade, sobre a definição da cidade enquanto espaço de pertencimento. $\mathrm{O}$ conflito sobre o nome da cidade é o signo de um conflito sobre os sujeitos que disputam a cidade enquanto "bem" e sobre qual seria o "bem" através do qual a cidade torna-se espaço.

O nome, portanto, individua a cidade, confere-lhe uma individualidade semiótica, mesmo onde a individuação espacial torna-se é algo complicado e inútil. O nome da cidade, por outro lado, é o que condensa a sua memória. A série de suas transformaçóes é o sismógrafo de sua história. De suas continuidades e descontinuidades, de sua existência e de seu ceder. Muito além do simples dado material. Como escreveu Petrarca sobre Roma, em 1373: "os muros e os prédios caíram, mas a glória de seu nome é imortal”. Um verso que o poeta escreve exatamente no momento em que tenta distinguir Roma de outras cidades mortas, como Troia ou Cartagena. Um exemplo interessante, já que - como demonstra o dialogo e a comparaçáo que Petrarca instaura com essas urbes desaparecidas - as duas cidades morta, na realidade, existem, e podem ser semioticamente ativas graças à presença mínima de seu nome, de seu nu permanecer. Permanecer que, por sua vez, pode levar a estudá-las, procurá-las e recriá-las, de forma parecida com o que acontece com as línguas mortas, que, afinal, encontram seus falantes.

De fato, uma cidade pode nascer e renascer de suas cinzas, ressurgir de nome em nome. $\mathrm{Ou}$, entre seus muitos nomes, perder o sentido de seu próprio devir.

Que história nos conta a sucessão, a sobreposição, o conflito e a confusão de Krly, Karalis, Calares, Santa Igia, Castel di Castro, Calari, Caller, Cagliari, Casteddu? Talvez que a história de uma cidade, de uma cidade qualquer, é apenas conflito e traduçáo, seja no momento em que assume muitos nomes, seja quando ela se identifica em um nome só.

\section{A cidade em expansáo}


O nome da cidade não marca simplesmente o sue articular-se no tempo, mas também no espaço. $\mathrm{O}$ nome cruza o espaço-tempo da cidade. $\mathrm{O}$ jogo complexo, entrecruzado, emaranhado entre ser e devir. Principalmente no que diz respeito às grande megalópoles contemporâneas.

Um bom exemplo é São Paulo, cujo nome encontra-se no cruzamento de uma transformação histórica e espacial. De um lado, São Paulo guarda - e, ao mesmo tempo, ultrapassa - as marcas do nome que lhe foi dado no 25 de Janeiro de 1554 pelo padres jesuítas Manuel da Nóbrega e José de Anchieta, que fundaram a cidade batizando-a de São Paulo de Piratininga. Do outro lado, São Paulo é o nó de uma rede que liga uma série de nomes criados para gerenciar o tumultuoso crescimento da metrópole. Sáo Paulo, portanto, com seus 11 milhôes de habitantes. Mas também a Região metropolitana de São Paulo, conhecida como "Grande São Pualo", que consta de 39 municípios e 20 milhóes de habitantes. E ainda o "Complexo Metropolitano Expandido", ou a "Macrometropole de São Paulo", que chegará a compreender mais de 30 milhôes de pessoas.

Este florescer de nomes aponta para um processo em ato. Uma dinâmica expansiva que, de fato, redefine constantemente os confins do que se chama "São Paulo". Não é difícil imaginar que, da mesma forma como Nova Iorque desdobrou-se, em sua fase de expansão, em uma assim chamada "New York" e a "Greater New York" que englobava os municípios limítrofes, São Paulo parece destinada a ser, no futuro, uma só cidade, que engloba todas aquelas que hoje a compóem.

\section{Poéticas metropolitanas.}

Os confins da cidade mudam, pluralizam-se, estratificam-se. A cidade engloba em si tudo o que antes era externo. A sua fisionomia geográfica e social transforma-se. Muda tanto a sua articulação interna, quanto a sua cartografia geral. A redefiniçấo de suas centros e periferias, de suas visibilidades e invisibilidades, de suas acessibilidade e inacessibilidade - lugar exclusivos ou de exclusão - ocorre sem parar.

Ao mesmo tempo, a cidade muda de pele através intervençóes microscópicas e infinitesimais. Lugares vazios enchem-se, outros esvaziam-se. Áreas verdes tornam-se cinzas, espaços abandonados transformam-se em hortas ou parques. Alguns bairros perdem o seu valor, outros emergem. O novo substitui o velho e o velho renova-se, sendo descoberto e requalificado.

O mesmo passado da cidade, o sue externo temporal, pode caber no espaço semiótico citadino, através de uma escavaçáo, de uma recuperaçáo, de uma valorização.

A paisagem da cidade muda sem parar. E, na crise que acompanha esta mutação, exalta-se o conflito sobre o valor da cidade. Perante a mudança é preciso tomar uma posição: agir para mudar ou agir para conservar. No entanto, entre os dois extremos existe uma grande variedade de possíveis formas de intervenção.

A paisagem da cidade é uma heterogeneidade em movimento. Porém, ela 
também sofre a ação as suas constantes. A partir de suas raízes morfológicas. Como também daquelas meteorológicas.

A paisagem da cidade, mistura irresolvível de natural e construído, ao ponto de náo ser nem totalmente natural e nem totalmente construída, possui seus ritmos, suas formas, suas cores, suas materialidades. A comunidade que vive a paisagem eleva algumas de suas porçóes a verdadeiras dominantes, a verdadeiros símbolos, a imagens de si própria. De maneira explicita, como quando um panorama torna-se emblemático ou um "skyline" transforma-se em logo. Ou como quando um determinado material - como o mármore travertino de Roma -, ou um fator atmosférico - a neblina em Londres - tornam-se estereótipos compartilhados.

Além disso, em um nível ainda mais profundo, a cidade se oferece como lugar de correlações dinâmicas. Fixações momentâneas de formas marcam de forma sutil e penetrante a percepção da cidade, da mesma maneira como as formas musicais que emergem em um determinado lugar parecem se juntar ao jogo de tensão e distensão encenado pela paisagem metropolitana, com seus morros e suas planícies, seus altos edifícios e suas casas baixas, suas construções modernas e os restos de seu passado, sues bairros populares e burgueses, suas estradas estreitas e suas grandes avenidas, seus vidros luminosos e suas pedras opacas. Portanto, em profundidade, no cruzamento entre o espaço e a comunidade, a cidade gera um sentimento, possui uma poesia própria. Uma poesia que temos que saber escutar e acompanhar - e que temos que reinventar antes que se torne um cliché desgastado.

O conjunto heterogêneo da cidade, de sua paisagem arquitetônica e antrópica, encontra nas formas culturais um espelho que abre um espaço para uma possível imagem de si, que é chamado a construir. Apesar de poder parecer efêmera ou parcial, esta imagem serve à cidade para individuar si mesma. E para deixar vislumbrar o bem comum que nela se esconde. 


\section{Referências Bibliográficas}

CARTOSIO, B. New York e il moderno. Società, arte e architettura nella metropoli americana 1876-1917. Milano: Feltrinelli, 2007.

CERVELLI, P. La città fragile. Roma : Lithos, 2008.

DAVIS, M. Planet of Slums. London: Verso, 2006.

GENINASCA, J. La parole littérarire. Paris : Presses Universitaires de France, 1997; trad. it. La parola letteraria. Milano: Bompiani, 2000.

GREIMAS. A. J. Pour une sémiologie topologique. In Sémiotique et sciences sociales. Paris: Seuil, 1976; trad. it., Per una semiotica topológica. In Semiotica e scienze sociali. Torino: Centro Scientifico Editore, 1995.

LOTMAN, J. M. Il simbolismo di Pietroburgo e i problemi della semiotica della città. In La semiosfera. L'asimmetria e il dialogo nelle strutture pensanti. Venezia: Marsilio, 1985.

. L'architettura nel contesto della cultura. In Il girotondo delle muse. Saggi sulla semiotica delle arti e della rappresentazione. Bergamo: Moretti \& Vitali, 1998.

MARRONE, G., PEZZINI, I., (a cura di). Linguaggi della città. Roma: Meltemi, 2008.

Ortu, G. G., (a cura di). Cagliari tra passato e futuro. Cagliari: CUEC, 2004.

PETRARCA, F. Invectiva contra eum qui maledixit Italie, 1373; Trad. it., In difesa dell'Italia. Venezia: Marsilio, 2004.

PEZZINI, I. (a cura di). Roma. Luoghi del consumo, consumo dei luoghi. Roma: Nuova Cultura, 2009.

SASSEN, S. Cities in a World Economy. Thousand Oaks: Pine Forge Press, 2000.

SEDDA, F. Le forme della città glocale. Percezioni, poteri, definizioni, in Imperfette traduzioni. Roma: Edizioni Nuova Cultura, 2012.

\section{Notas}

(1)Trata-se do RodoAnel que circunda a capital italiana (N. do T.) 